\title{
Methodological problems of human social security: legal and economic discourse
}

\author{
Raviia Faritovna Stepanenko ${ }^{1,2 *}$, Alsu Rinatovna Garifullina ${ }^{3}$, Larisa Vladimirovna Yun ${ }^{3}$, \\ Iskander Anvarovich Sadykov ${ }^{2}$, Eduard Yevgenyevich Isayev ${ }^{1}$ \\ ${ }^{1}$ Kazan (Volga Region) Federal University, Department of Theory and History of State and Law, \\ Kazan, Russia \\ ${ }^{2}$ University of Management "TISBI", Department of Theory and History of State and Law, Kazan, \\ Russia \\ ${ }^{3}$ Kazan Branch of Russian State University of Justice, Department of State and Legal Disciplines, \\ Kazan, Russia
}

\begin{abstract}
The article examines the current problems of legal and economic nature in resolving the acute social situation associated with negative trends in the global community: the demographic crisis, high mortality, deep social stratification of society, etc. The methodological basis of the study are universal, general scientific and particular scientific methods of cognition used by the legal science in the object-subject sphere of cognition of the general theory of law. In addition, a number of synthetic, integrative ways of research are used, which are part of the methodology of interdisciplinarity, relevant for modern socio-humanitarian science. The work proves that the traditional methodological approaches of economic and legal theories are less and less adequate to the new needs of the humanities and increasingly require them to combine their efforts in the knowledge of profound socio-economic problems. The main innovative tool for solving many social problems today is program-project management, which involves passing through a series of stages: analytical (the need for a problem-oriented analysis of situations; conceptualization (selection and justification of goals and objectives); instrumentalization (selection of effective means to achieve goals and objectives); specification of the scheme of activities in their implementation; budgeting of the project; identifying the criteria of effectiveness in the implementation of the project from the perspective of socially-oriented development of the economy, studied jointly by law and economics. The novelty of the work lies in the proof of the hypothesis formulating the need to justify such an independent direction of the Russian theory of legal policy as - legal economic policy, which confirms the feasibility of the cumulative view of the range of existing problems.
\end{abstract}

Keywords: law, economics, interdisciplinarity, legal policy, social protection, constitutional rights

\footnotetext{
*Corresponding author: stepanenkorf@yandex.ru
} 


\section{Introduction}

Globalization processes, which change the fundamentally established traditions in the economic, legal, and sociocultural fields of personal and interstate interactions, largely modifies the scientific field of humanitarian research as well. What once seemed to be strictly differentiated by fields and subjects of study is becoming increasingly contingent on the boundaries of cognition. Humanity, faced with enormous political, economic, and environmental challenges, has largely found itself in states of uncertainty, marginality, and social insecurity. While placing high expectations on the states in which citizens reside, expectations of social protection and assistance are sometimes not met. The autonomous development of the economy and law, unnoticed in the stable functioning of states in the international space, demonstrates its inconsistency in the face of unpredictable events, such as the coronavirus pandemic.

The domestic general theory of law, the formation of which fell in the second half of the $20^{\text {th }}$ century in Russia, is acquiring its relevance today for the study of many new problems that require an interdisciplinary approach in their conceptual study [1]. Such a fundamental direction of the general theory of law as legal policy, largely implementing in its research the interdisciplinary content of social problems, today gets its development in the field of theoretical jurisprudence.

The common interest of economic and legal theory in the recognition of social problems of today becomes fundamental and requires the unification of these scientific disciplines, both in Russia and abroad.

The most acute problems today are poverty, unemployment, social insecurity of citizens. Under these conditions, the role of states in the sphere of legal regulation of socio-economic processes, important for the observance and protection of constitutional rights and freedoms of citizens, increases significantly. The justification of new methodological approaches both in scientific research and in the development of new strategies of activity interaction between economics and law is required. The authors believe that a methodologically important dualistic understanding of human social insecurity in an era of enduring uncertainty and anxiety, the growth of new threats of various kinds, should contribute to the development of a unified scientific position that helps to overcome contemporary problems.

\section{Materials and methods}

The methodological basis of the research are universal, general scientific and particular scientific methods of cognition, used by the legal science in the object-subject sphere of cognition of the general theory of law. In addition, a number of synthetic, integrative ways of research are used, which are part of the methodology of interdisciplinarity, relevant for modern socio-humanitarian science.

\section{Results and discussion}

Theoretical and methodological formulation of the problem, on which the attention was focused, gives the general theory of law grounds for scientific justification and formulation of legal economic policy that can rationally and effectively develop social, fiscal, financial, tax and other areas of the economy only on the basis of the rule of law. In this direction of legal policy, the dominant role should belong to the observance and protection of the constitutional social and economic rights of all citizens [2], formally enshrined in legislation by establishing, among other things, the economic and legal status of socially vulnerable groups (individuals). 
Exploring the theoretical and methodological features of the establishment of legal status in general [3], in domestic law, for example, Tishaev in the work [4] justifies the expediency of introducing its special variant - economic and legal status. "Today there is hardly anyone who would seriously argue that anyone (no matter whether an individual or a social group) can in modern conditions be outside the economic and legal environment and build their behaviour without taking into account the regularities of economic and legal development of the state and society. Another thing is that from the point of view of law, the economy can be both legal (official) and shadow (unofficial), or criminal (criminal)", the researcher notes [4]. Tishaev within the framework of the hypothesis of the existence of "economic law" as an independent legal category and "legal economy" as a formally functioning concept in legal science, differentiates socio-economic rights of citizens into two independent legal constructs: "social" and "economic" rights and freedoms [4]. And the latter, according to the author, are primary in relation to the social [4], which seems to us, very debatable, but important in the mainstream of the issues under consideration.

Here it is appropriate to note the problem of "exploitation of man by man", so thoroughly studied by K. Marx with his formulation of the question about the transient nature of capitalism and the issues of alienation of man from the results of labor [5]. In this sense, modern legal and economic studies are increasingly turning to Marx's seminal work, attempting to find answers to the question of what capitalism can or could do to resolve the current situation. After all, the social is not crucial to the capitalist mode of production and is by no means its task.

The author of the monographic study [6] calls the "brilliant reticence" of the general economic theory of the legal content of certain economic processes (competition, monopolism, producer and consumer interests, etc.) The consequences of the irrational exclusion of legal principles and aspects in the concept of behavioral economics, can indeed become uncertainty, pretense, sham, finally - illegality of behavior of economic agents or actors of the relevant social relations. Economic relations, as well as the goals of achieving positive socio-economic development of society, prospectively must have antecedent (predicate) legal standards of legitimate economic behavior at different levels (individual, collective, state). Such gradation of subjects (participants) of economic relations is most subjectively presented in law (physical and legal persons, the state as a collective subject of legal relations, etc.), but in a certain way are not taken into account in the perspective of forecasting, for example, by behavioral economics, which focuses mainly on utilitarian problems of consumers or producers, for example, in the shadow economy.

As the Prosecutor of the Republic of Tatarstan I.S. Nafikov: "The shadow economy and crime have formed into a kind of integrative - holistic phenomenon ... that generates once healthy areas of social life, undermining the fundamentals of social development ... The global shadow economy is comparable in size to the US economy, which generates the largest GDP in the world" [7]. This statement of problems is equally important for economic and legal scientific disciplines considered in the concept of legal economic policy of the social state [8].

As Popov and Semyachkov note in their work [9] the indicators of such development include demographic, educational, housing, informational, cultural, environmental, social and psychological well-being of the country's population. The composite indicator takes into account, as is known, more than 50 indicators included in three main groups: 1) basic human needs; 2) basics of human well-being; and 3) human development opportunities [9].

Indicators of efficiency of the economy, as well as legal institutions are not included in this index, which, in our opinion, should stimulate a deep scientific interest in the stated problem from the point of view of studying the direct dependence of social well-being of the population on the efficiency of both law and economy. Also of scientific interest is predetermined by the possibilities of institutions of responsibility, which can be used in cases 
of reduction of these indicators through the fault or due to negligence in the performance of their official duties by authorized special subjects of law.

It seems that the relationship between the categories of "legal responsibility" and "legal irresponsibility" may be of significant scientific interest for the concept of behavioral economics, which actively uses the category of "opportunistic behaviour" in constructing models of "economic man" (J. Keyes et al.). "Opportunistic behaviour", in our opinion, which accumulates mainly psychological problems related to the extraction of benefit, profit and income (D. Kahneman, A. Tversky, P. Slovik and others), simultaneously virtually ignores the "legal component" of the negative, often, consequences of such behavior. In this regard, it is the joint cognition of the behavioral paradigm of the concepts of "legal" and "economic" man, as well as the hypothesis of legal responsibility and irresponsibility, that represent the synergy of the interests of jurisprudence and economic theory.

The individual authors of this paper have not escaped this temptation either, having considered (most likely at the propaedeutic level) some patterns of the concept of economic analysis of law, attempting to interpret legal activity as a transaction in its foreign sense.

In the work [10] we conducted a brief analysis of the works of Russian jurists and economists (A.A. Auzan, E.M. Ashmarina, V.V. Ershov, V. Kornev, M.Y. Malkina, etc.) and foreign scholars (D. Commons, D. North, P. Ollil, N. Eggerson, K. Arrow and others) [11, 12].

As a result of this analysis were proposed indicators of the effectiveness of legislation of economic nature and a typology of transaction costs, contributing, according to the authors, the development of methodological tools in the knowledge of the problems of socioeconomic properties and the role of normativity in their minimization with the help of the methodological tools of the general theory of law.

As is well known, "normativism" and "positivism" in jurisprudence are not interested in truth, it is only a fact of consistency of norms. Earlier, the famous Russian civilist Gambarov argued that: “...legal dogma and positive law, in a certain sense, is a "dream world" created by the will of the legislator and detached from reality" [13]. Critical analysis of normativism and positivism, in the spirit of opposition to the analytical school of law and the logical positivism of H. Kelsen, in the modern general theory of law substantiates the specifics of the Russian perception of law not from a legal but a moral perspective. "Normativism" in legal dogmatic combines legal concepts, principles and technologies - as instruments of regulatory and protective influence. But the results of positivist, including normativist legal understanding [14] do not contribute to the full disclosure of the economic content of law, so necessary for real results for the social state.

The discourse on the social justice of law, and the economy as well, for example, in the work of F. Hayek, who has already been quoted, is marked by a sharp criticism of the moral and value postulates of law [15]. The author speaks of demagogy and the lack of content in the category of "social justice", convincing the reader that it should not be used in a "free society". As an opponent of the socialist order, Hayek also seems to call "economic justice" a meaningless notion, giving importance to fair judicial decisions [15]. (Friedrich August von Hayek, 2006), which, in our opinion, devalues the spiritual and material realities and absolutes of law and economics, as already noted [15].

\section{Conclusion}

Modern analytical scientific activity, based on one of the leading methodological principles of modern science - interdisciplinarity, demonstrates today the need for an integral vision and solution of legal and economic problems at the general theoretical and applied levels. Complemented and added to as necessary by the scientific experience and practices of sociohumanitarian studies (philosophy, economics, political science, sociology, history, 
psychology, etc.), the methodological paradigm of analytical activity requires the "inclusion" of both natural-science and technical-scientific practices involved in the social transformations of state organizations into humanitarian knowledge.

\section{References}

1. Khazieva N.O., Khaziev A.Kh., Klyushina E.Vl., Stepanenko G.N., Stepanenko R.F. "Friends" and "foes" in the social space of the tatar ethnic group. Journal of History Culture and Art Research. 2017. T. 6. № 4. P. 1237-1244. DOI:10.7596/taksad.v6i4.1162

2. A.R. Garifullina, L.V. Yun, Constitutional Justice in Russia and Croatia: Comparative Legal Analysis. Russian Judge, No. 5, P. 39-43 (2020). https://doi.org/10.18572/18123791-2020-5-39-43

3. L.T. Bakulina, Methodology of the tiered approach in the study of contractual legal regulation. Methodology of the tiered approach in the study of contractual legal regulation. Perm University Bulletin. Legal sciences. 2015. No. 3 (29). S. 77-81. (2015)

4. B.B. Tishaev, Ekonomika - Pravovoy status lichnosti: strukturno-soderzhatelnyi analiz [Economics-legal status of a person: structural and content analysis], $\mathrm{PhD}$ thesis (Samara, 2011), $195 \mathrm{p}$.

5. N.O. Khazoeva, A.K. Khaziev, E.V. Klyushina, G.N. Stepanenko, R.F. Stepanenko, Marxism in the modern world: social-philosophical analysis. Utopia y Praxis Latinoamericana, 2019. T. 24. № Extra 5. C. 51-56.

6. S.V. Korolev, A brief history of economic doctrines in the focus of the theory of law: a monograph (Yustitsinform Publ., Moscow, 2017)

7. I.S. Nafikov, Shadow economy and organized crime in the conditions of a big city: monograph, in V.P. Malkov (ed.) (Poznanie Publ., Kazan, 2012)

8. I.A. Sadykov, Goals and objectives of the legal economic policy of the social state: general theoretical aspects. Bulletin of the Kazan Law Institute of the Ministry of Internal Affairs of Russia. 2020. Vol. 11.No. 2 (40). P. 164-169.The Bulletin of the Kazan Law Institute of MIA of Russia, https://doi.org/10.37973/kui.2020.56.89.003IA

9. E.V. Popov, K.A. Semyachkov, Economic development problems. Economic revival of Russia. 2018. No. 3 (57). - P. 63-70. (2018)

10. Stepanenko R.F., Kamarov M.R. Legal understanding of transaction costs. Humanities and Social Sciences Reviews. 2019. T. 7. № 6. C.668-672. (2019). https://doi.org/10.18510/hssr.2019.76100

11. A.A. Auzan, The economy under the pandemic and afterwards. Population and Economics, 4(2), 4-12 (2020). https://doi.org/10.3897/popecon.4.e53403

12. J.R. Commons, Institutional Economics. American Economic Review, 21, 652 (1931)

13. Y.S. Gambarov, Civil law: General part (Zertcalo Publ., Moscow, 2003)

14. Yun L.V. Modern legal thinking in the evolution of Russian legal culture in the postSoviet period Dissertation for the degree of candidate of legal sciences / Kazan (Volga region) Federal University. Kazan, 2019

15. Friedrich August von Hayek, Law, Legislation and Freedom (IRISEN Publ., Moscow 2006) $-644 \mathrm{p}$. 